\title{
Insulin Like Growth Factor-2 Measurement
}

National Cancer Institute

\section{Source}

National Cancer Institute. Insulin Like Growth Factor-2 Measurement. NCI Thesaurus. Code C74865.

The determination of the amount of insulin-like growth factor- 2 present in a sample. 